Carlo Asuni

Alessandra Cherchi

Donatella Congiu

Maria P. Piccardi

Maria Del Zompo

Maria E. Stochino

\section{Association study between clinical response to rizatriptan and some candidate genes}

Received: 27 November 2006

Accepted in revised form: 19 February 2007

Published online: 11 June 2007
C. Asuni $(\varangle) \cdot$ A. Cherchi • D. Congiu •

M.P. Piccardi • M. Del Zompo •

M.E. Stochino

Section of Clinical Pharmacology,

Department of Neurosciences

"B.B. Brodie", University of Cagliari,

P.O. San Giovanni di Dio,

Via Ospedale 46, I-09124 Cagliari, Italy

e-mail: carloasuni@tiscali.it

Tel.: +39-070-6092438

Fax: +39-070-653584

\begin{abstract}
The aim of this study was to test genetic differences in the clinical response to rizatriptan in patients affected by migraine without aura. These genetic differences could be explained by various genes, the HTR1B, encoding the $5-\mathrm{HT}_{1}$ receptor subtype, MAOA gene that encodes the monoamino-oxidase, the main metabolic enzyme of this triptan, SLC6A4 (gene encoding the serotonin transporter) and $\mathrm{DRD}_{2}$ (gene encoding the $\mathrm{D}_{2}$ receptor), both involved in the pathogenesis of migraine. Fifty unrelated patients affected by migraine without aura (IHS) were included. Patients were divided into two groups (respon-
\end{abstract}

ders and non-responders) according to clinical response. Thirty-one out of fifty patients responded to rizatriptan. A significant difference among the two groups was observed in both allele $(p=0.02)$ and genotype distribution $(p=0.03)$ of DRD2/NcoI. The significant association with the DRD2/NcoI polymorphism in responders suggested that the DRD2/NcoI C allele may be considered a susceptibility factor heralding a good response to rizatriptan.

Keywords Migraine $\cdot$ Triptans • Pharmacogenetics $\cdot$ Dopamine • DRD2

\section{Introduction}

Migraine is a complex genetic disease, wherein susceptibility genes and environmental factors both contribute to its development. Moderate to severe migraine attacks are usually treated with triptans, specific anti-migraine drugs. Nevertheless, up to $15 \%$ of migraineurs fail to respond to triptans. As multiple clinical and genetic factors may contribute towards inter-patient difference in the clinical response to drugs, several studies have been performed to characterise the response and non-response to triptans [1].

Rizatriptan is a $5-\mathrm{HT}_{1 \mathrm{~B}}$ receptor agonist, which has proved to be considerably efficient in treating migraine attacks [2]. Genetic differences in the clinical response to rizatriptan could be explained by various genes, namely the one encoding the 5-HT $\mathrm{H}_{1}$ receptor subtype (HTR1B gene), representing the pharmacological target of the drug, and that encoding the monoamino-oxidase (MAO-A gene), the main metabolic enzyme of this triptan.

The pathogenesis of migraine is not yet fully understood but both neural and vascular mechanisms are known to be involved [3, 4]; moreover, an altered monoaminergic neurotransmission has also been implicated, particularly of serotonergic and, more recently, dopaminergic systems 
[5]. In this regard, some authors have reported an association between migraine and the gene of $\mathrm{D}_{2}$ dopaminergic receptors $[6,7]$.

When undertaking studies of pharmacogenetics, it would be advisable to also consider genes related to the pathogenesis of the disease as possible candidates. Indeed, should the drug prove to be clinically effective, it is reasonable to hypothesise that it will affect key mechanisms, although not in a direct manner.

Thus, we designed a prospective study to test the hypothesis that genetic variation might be one of the factors responsible for the resistance to therapy observed in patients affected by migraine without aura (MOA) treated with rizatriptan. In our sample we carried out an association study with the HTR1B, the MAO-A and the DRD2 genes. We chose the polymorphisms on the basis of a hypothesised functional role or on the basis of already positive association studies with migraine.

\section{Methods}

Patients

Fifty unrelated male and female patients (45 women, 5 men; age 19-50 years), all Sardinian, affected by MOA (IHS criteria), consecutively admitted to our Headache Centre (HC), were included in the study. The length of the study was one and a half years. Symptomatic headaches were excluded by clinical examination, Doppler sonography and, when necessary, by CT scan or MRI. A direct interview was conducted by the physicians of the $\mathrm{HC}$ with experience in headache diagnosis. Clinical and demographic data of each patient were collected. Familiarity was evaluated only on the first degree relatives. The patients filled in a diary reporting the following features: number and duration of migraine attacks, intensity of migraine on the usual 4-step scale: 0 , none; 1 , mild; 2 , moderate; 3 , severe headache; presence of associated symptoms; number of rescue medications requested (rizatriptan $10 \mathrm{mg}$ ); need for rescue medications other than the selected triptan. Response and non-response for each patient were estimated using data recorded in the diary. Migraineurs were eligible for inclusion only if they had treated at least five migraine attacks with $10 \mathrm{mg}$ oral rizatriptan. The study was carried out in accordance with the Declaration of Helsinki and was approved by the local Ethics Committee. Informed consent was obtained from all subjects before participation in the study.

The patients were divided into two groups (responders and non-responders) according to their clinical response to $10 \mathrm{mg}$ oral rizatriptan. Clinical response was defined as being pain-free within two hours of rizatriptan intake according to IHS Guidelines.

Patients who were pain-free within two hours after $10 \mathrm{mg}$ oral rizatriptan in at least four out of five migraine attacks were defined as "responders". Patients who were not pain-free in at least three of five consecutively treated migraine attacks were defined as "non-responders" [8]. Patients with partial response to rizatriptan were excluded from genotyping.

\section{Genotyping}

High-molecular weight genomic DNA was extracted from peripheral blood leukocytes according to standard procedures.

\section{$D_{2}$ receptor gene (DRD2) polymorphisms}

Polymerase chain reaction (PCR) and NcoI restriction fragment length polymorphism (RFLP)

The silent $\mathrm{C} / \mathrm{T}$ transition (His313His) located in exon 6 was analysed according to the method of Sarkar et al. [9]. PCR products, a 446-bp fragment, were digested with NcoI restriction enzyme. Digested products were separated on $1.5 \%$ agarose gel. The restriction profiles were visualised by ethidium bromide staining.

\section{PCR and BstNI RFLP}

The $-141 \mathrm{C}$ Ins/Del variant in the promoter region of the DRD2 was analysed according to Arinami et al. [10]. The PCR products, a 304-bp (insertion variant) or 303-bp fragment (deletion variant), were digested with restriction enzyme BstN I (BioLabs). Alleles were resolved by a $2 \%$ agarose gel electrophoresis and were visualised by ethidium bromide staining.

Serotonin transporter gene (SLC6A4)

Insertion/deletion polymorphism in the 5 ' promoter region of the SLC6A4 was detected according to the method described by Lesch et al. [11]. PCR products were separated on $2 \%$ agarose gels supplemented with ethidium bromide allowing differentiation of the long (528 bp) and short (484 bp) variant.

\section{5- $H T 1 D_{\beta}$}

A silent mutation substitution at nucleotide 861 of the coding region was detected by PCR-based HincII restriction digestion assay according to Lappalainen et al. [12]. The PCR product, a fragment of $548 \mathrm{bp}$, was digested with the restriction enzyme HincII and the digested products were separated on $2 \%$ agarose gels supplemented with ethidium bromide allowing differentiation of the $\mathrm{G}$ (452 bp and $96 \mathrm{bp}$ ) and C (309 bp and $143 \mathrm{bp}$ ) allele.

\section{MAO-A}

The determination of the polymorphism for EcoRV in MAO-A gene was performed according to Hotamisligil and Breakefield [13]. A 488-bp fragment indicates the presence of $\mathrm{N}$ allele $(\mathrm{N}=$ no EcoRV restriction site) and a 456-bp fragment indicates the presence of $\mathrm{Y}$ allele ( $\mathrm{Y}=$ presence of EcoRV restriction site). 
Genotypes were scored independently by two experienced investigators unaware of the clinical data. Differences were resolved by repeating the typing of the individual in question.

Statistical analysis

Deviation from the genotype counts predicted by HardyWeinberg equilibrium expectations was tested using HWE program [14]. Fisher's exact test was used to compare allelic frequencies. Variation in genotype frequencies was tested by $2 \times 3 \chi^{2}$ contingency table analysis. We used the CLUMP_New [15] program to estimate empirical significance values of the $\chi^{2}$ statistic (T1) using 10000 Monte Carlo simulations. We applied data with non-corrected $\mathrm{p}$ values as the appropriate correction for nonindependent multiple testing is controversial for genetic studies of complex diseases.

When multiple tests are performed, an increased rate of type I errors should be anticipated but, in an exploratory design, a correction might unacceptably inflate the number of type II errors.

\section{Results}

Demographic and clinical data of the 50 patients affected by MOA included in the study are shown in Table 1 . Thirty-one out of fifty patients $(62 \%)$ were considered good responders to rizatriptan. There were 13 non-responders (26\%). Six patients ( 5 women +1 man) were partial responders to rizatriptan, thus they were not genotyped. The two genotyped patient groups did not differ significantly in the items studied. The percentage of patients with associated symptoms such as nausea and vomiting were similar in both responder and non-responder groups (Table 2).

The genotypic counts were in Hardy-Weinberg equilibrium in rizatriptan responders and non-responders at these polymorphic loci.

No significant differences were observed in allele and genotype frequencies of HTR1B, MAO-A, SLC6A4 and DRD2/BstNI polymorphisms (Table 3).

As shown in Table 4, allele distribution of DRD2 was significantly different in responders and non-responders $(p=0.02, \mathrm{OR}=3.68,95 \% \mathrm{CI}: 1.27-10.62)$. Genotype distribution among the two groups also differed significantly $\left(\chi^{2}=6.21, \mathrm{df}=2, p=0.03\right)$.

\section{Discussion}

The cumulative data obtained with the trials of rizatriptan as well as with reports from clinical practice make rizatriptan $10 \mathrm{mg}$ an indicated oral triptan for migraine patients. However, despite its effectiveness, the use of triptans does not result in complete relief of migraine in all patients. However, response to treatment is difficult to define, in view of the variability of individual responses to any pharmacologic treatments in migraineurs, representing a troublesome obstacle for general interpretation. In the absence of encoding definition criteria for responders and non-responders to triptans in the literature, we have chosen the definition of response as at least 4 successful treatments with $10 \mathrm{mg}$ rizatriptan in five attacks $[1,16]$, as it has proved the most reliable to date.

A total of $62 \%$ responders to rizatriptan were evidenced, similar to data already published [2].

In the present study, allele frequencies in the HTR1B, MAO-A and DRD2/BstNI polymorphisms did not differ between responders and non-responders. These negative results are not very meaningful due to the relatively small size of our sample and a gene that has minor contribution

Table 1 Demographic and clinical characteristics of the sample

\begin{tabular}{|c|c|}
\hline \multicolumn{2}{|l|}{$\operatorname{Sex}(\%)$} \\
\hline $\mathrm{M}$ & $5(10)$ \\
\hline $\mathrm{F}$ & $45(90)$ \\
\hline Familiarity (\%) & $40(86 \%)$ \\
\hline \multicolumn{2}{|l|}{ Age } \\
\hline Mean \pm SD & $34.6 \pm 8.3$ \\
\hline Median & 33 \\
\hline \multicolumn{2}{|l|}{ Age at onset } \\
\hline Mean \pm SD & $15.5 \pm 6.8$ \\
\hline Median & 14 \\
\hline \multicolumn{2}{|l|}{ Age at diagnosis } \\
\hline Mean \pm SD & $31.9 \pm 7.9$ \\
\hline Median & 31 \\
\hline \multicolumn{2}{|l|}{ Years of illness } \\
\hline Mean \pm SD & $17.7 \pm 8.7$ \\
\hline Median & 16 \\
\hline \multicolumn{2}{|l|}{ Frequency of attacks (\#/month) } \\
\hline Mean \pm SD & $3.8 \pm 2.7$ \\
\hline Median & 3 \\
\hline \multicolumn{2}{|l|}{ Length of attacks in hours } \\
\hline Mean \pm SD & $48 \pm 18.8$ \\
\hline Median* & 48 \\
\hline \multicolumn{2}{|l|}{ Intensity of attacks (\# of patients) } \\
\hline Moderate & $36(72 \%)$ \\
\hline Severe & $14(28 \%)$ \\
\hline Nausea (no. of patients) & $48(96 \%)$ \\
\hline Vomiting (no. of patients) & $33(66 \%)$ \\
\hline Phonophobia (no. of patients) & $40(80 \%)$ \\
\hline Photophobia (no. of patients) & $40(80 \%)$ \\
\hline Intolerance to movement (no. of patients) & $42(84 \%)$ \\
\hline Yawning (no. of patients) & $13(26 \%)$ \\
\hline
\end{tabular}


Table 2 Demographic and clinical characteristics of responder (R) and non-responder (NR) patients to rizatriptan

\begin{tabular}{|c|c|c|}
\hline & $\mathrm{R}(\# 31)$ & NR (\#13) \\
\hline \multicolumn{3}{|l|}{ Age } \\
\hline Mean \pm SD & $36.2 \pm 9$ & $32.2 \pm 5.4$ \\
\hline Median* & 33 & 31 \\
\hline \multicolumn{3}{|l|}{ Age at onset } \\
\hline Mean \pm SD & $15.6 \pm 6.5$ & $14.3 \pm 6$ \\
\hline Median* & 14 & 13 \\
\hline \multicolumn{3}{|l|}{ Age at diagnosis } \\
\hline Mean \pm SD & $33.3 \pm 8.3$ & $30.6 \pm 5.6$ \\
\hline Median* & 31 & 30 \\
\hline \multicolumn{3}{|l|}{ Years of illness } \\
\hline Mean \pm SD & $18.9 \pm 9.2$ & $16.9 \pm 5.6$ \\
\hline Median* & 16 & 17 \\
\hline \multicolumn{3}{|l|}{ Frequency of attacks (\#/month) } \\
\hline Mean \pm SD & $3.8 \pm 3$ & $3.4 \pm 1.7$ \\
\hline Median* & 3 & 3 \\
\hline \multicolumn{3}{|l|}{ Length of attacks in hours } \\
\hline Mean \pm SD & $45.3 \pm 17.2$ & $54.5 \pm 21.2$ \\
\hline Median* & 48 & 72 \\
\hline \multicolumn{3}{|l|}{ Intensity of attacks (\# of patients) ${ }^{* *}$} \\
\hline Moderate & $24(77 \%)$ & $8(62 \%)$ \\
\hline Severe & $7(23 \%)$ & $5(38 \%)$ \\
\hline Nausea (no. of patients) $* *$ & $31(71 \%)$ & $11(85 \%)$ \\
\hline Vomiting (no. of patients)** & $22(71 \%)$ & $5(38 \%)$ \\
\hline Phonophobia (no. of patients)** & $23(74 \%)$ & $12(92 \%)$ \\
\hline Photophobia (no. of patients) ${ }^{* *}$ & $23(74 \%)$ & $12(92 \%)$ \\
\hline $\begin{array}{l}\text { Intolerance to movement } * * \\
\text { (no. of patients) }\end{array}$ & $24(77 \%)$ & $13(100 \%)$ \\
\hline Yawning (no. of patients)** & $9(29 \%)$ & $2(15 \%)$ \\
\hline
\end{tabular}

* non significant $p>0.05$ Mann-Whitney test

** non significant $p>0.05 \chi^{2}$

could not be detected. Moreover, other authors have shown negative results on association studies between migraine and the genes of $5-\mathrm{HT}_{1 \mathrm{~B}}$ and $5-\mathrm{HT}_{1 \mathrm{~F}}[16,17]$.

A significant association in allelic frequency of the DRD2/NcoI polymorphism was found in responders to rizatriptan. In fact, a significant increase is observed in the frequency for the $\mathrm{C}$ allele among responders compared to non-responders, suggesting that this allele may be considered a susceptibility factor heralding a good response to rizatriptan. This polymorphism is a silent mutation and may serve as an associated marker through linkage disequilibrium with other functional mutations. In the present study, we speculate that the $\mathrm{C}$ allele may be in linkage disequilibrium with other functional mutations in the DRD2 gene.

The role of the dopaminergic system in migraine has also been suggested on the basis of genetic evidence. It has
Table 3 Genotype and allele frequencies of SLC6A4, 5-HT1D MAO-A and DRD2/BstNI polymorphisms in rizatriptan-responsive and non-responsive individuals

\begin{tabular}{|c|c|c|c|c|c|}
\hline \multirow[b]{2}{*}{ SLC6A4 } & \multicolumn{3}{|c|}{ Genotype } & \multicolumn{2}{|c|}{ Allele } \\
\hline & 11 & ls & ss & 1 & $\mathrm{~s}$ \\
\hline Responder (\#31) & 11 & 14 & 6 & 36 & 26 \\
\hline Non-responder (\#13) & 6 & 5 & 2 & 17 & 9 \\
\hline \multirow[t]{2}{*}{$\chi^{2}=2.87 ; p=0.26$} & \multicolumn{5}{|c|}{$p=0.63$} \\
\hline & \multicolumn{3}{|c|}{ Genotype } & \multicolumn{2}{|c|}{ Allele } \\
\hline${ }^{5-H T 1 D}{ }_{\beta}$ & GG & $\mathrm{GC}$ & $\mathrm{CC}$ & G & $\mathrm{C}$ \\
\hline Responder (\#31) & 21 & 9 & 1 & 51 & 11 \\
\hline Non-responder (\#13) & 11 & 2 & 0 & 24 & 2 \\
\hline \multirow[t]{2}{*}{$\chi^{2}=1.46 ; p=0.61$} & \multicolumn{5}{|c|}{$p=0.32$} \\
\hline & \multicolumn{3}{|c|}{ Genotype } & \multicolumn{2}{|c|}{ Allele } \\
\hline MAO-A & $\mathrm{NN}$ & NY & YY & $\mathrm{N}$ & $\mathrm{Y}$ \\
\hline Responder (\#29) & 19 & 8 & 2 & 46 & 12 \\
\hline Non-responder (\#11) & 6 & 3 & 2 & 15 & 7 \\
\hline \multirow[t]{2}{*}{$\chi^{2}=2 ; p=0.67$} & \multicolumn{5}{|c|}{$p=0.39$} \\
\hline & \multicolumn{3}{|c|}{ Genotype } & \multicolumn{2}{|c|}{ Allele } \\
\hline DRD2/BstNI & II & ID & $\mathrm{DD}$ & I & $\mathrm{D}$ \\
\hline Responder (\#31) & 28 & 3 & 0 & 59 & 3 \\
\hline Non-responder (\#13) & 13 & 0 & 0 & 26 & 0 \\
\hline$\chi^{2}=1.352 ; p=0.55$ & & & & $p=0.55$ & \\
\hline
\end{tabular}

Table 4 DRD2/NcoI allele and genotype frequency

\begin{tabular}{lrccc}
\hline & \multicolumn{2}{c}{ Allele } & \multicolumn{2}{c}{ Genotype } \\
& C & T & CC CT & TT \\
\hline $\begin{array}{l}\text { Responder } \\
(\# 31)\end{array}$ & $53(0.85)$ & $9(0.15)$ & $24(0.77) 5(0.16) 2(0.07)$ \\
$\begin{array}{l}\text { Non-responder 16 (0.62) } \\
(\# 13)\end{array}$ & $10(0.38)$ & $5(0.38) 6(0.46) 2(0.16)$ \\
\hline
\end{tabular}

$p=0.02$ Fisher's exact test $\chi^{2}=6.21 ; p=0.03$;

O.R. $=3.68,95 \%$ C.I. $=1.27-10.62$

recently been suggested that genetic variations within the dopaminergic system may underlie clinical susceptibility to migraine, although additional genetic, biochemical and clinical studies should be undertaken [18]. In this regard, findings reported by basic studies may be of interest. The 
dopaminergic system has been implicated in the regulation of cerebral cortical microcirculation and disturbances in central dopaminergic neurotransmission have been shown to alter cerebrovascular regulation and blood-brain barrier permeability [19]. Moreover, it has been reported that dopamine strongly and selectively inhibits the vascular permeability and the angiogenic activities of permeability factor/vascular endothelial growth factor (VPF/VEGF), acting through the D2 receptors [20].

The data show that the genotype and allele frequencies for the DRD2/NcoI polymorphism differ between the responder and non-responder groups we studied $(p=0.03$, $p=0.02$ ). This preliminary study provides some evidence that the DRD2 variant is associated with clinical response to rizatriptan. In conclusion, in spite of the small size of the sample examined and the need of replication in other types of populations, this study underlines the possible usefulness of a pharmacogenetic strategy as a tool to study potential drug targets.

Acknowledgments This study was the subject of the thesis presented by one of the authors (Carlo Asuni) for his Master's Degree in Headache Medicine, "La Sapienza" University of Rome, II School of Medicine and Surgery, Academic Years 2005-2006. This study was partially supported by a grant from the University of Cagliari. No financial relationship exists between the authors and Merck Sharp \& Dohme and Neopharmed, the producers of rizatriptan.

\section{References}

1. Visser WH, Burggraaf J, Muller LM et al (1996) Pharmacokinetic and pharmacodynamic profiles of sumatriptan in migraine patients with headache recurrence or no response. Clin Pharmacol Ther 60:452-460

2. Ferrari MD, Roon KI, Lipton RB, Goadsby PJ (2001) Oral triptans (serotonin $5-\mathrm{HT} 1 \mathrm{~B} / 1 \mathrm{D}$ agonists) in acute migraine treatment: a meta-analysis of 53 trials. Lancet 358:1668-1675

3. Waeber C, Moskowitz MA (2003) Therapeutic implications of central and peripheral neurologic mechanisms in migraine. Neurology 61[Suppl 4]: S9-S20

4. Maassen VanDenBrink A, Van Den Broek RWM, De Vries R et al (2000) Craniovascular selectivity of eletriptan and sumatriptan in human isolated blood vessels. Neurology 55:1524-1530

5. Peroutka SJ (1997) Dopamine and migraine. Neurology 49:650-656

6. Peroutka SJ, Wilholt T, Jones K (1997) Clinical susceptibility in migraine with aura is modified by dopamine D2 receptor (DRD2) NcoI alleles. Neurology 49:201-206

7. Del Zompo M, Cherchi A, Palmas MA et al (1998) Association between dopamine receptor genes and migraine without aura in a Sardinian sample. Neurology 51:781-786
8. Mathew NT, Kailasam J, Gentry P, Chernyshev O (2000) Treatment on nonresponders to oral sumatriptan with zolmitriptan and rizatriptan: a comparative open trials. Headache 40:464-465

9. Sarkar G, Kapelner S, Grandy DK et al (1991) Direct sequencing of the dopamine D2 receptor (DRD2) in schizophrenics reveals three polymorphisms but no structural change in the receptor. Genomics 11:8-14

10. Arinami T, Gao M, Hamaguchi H, Toru M (1997) A functional polymorphism in the promoter region of the dopamine D2 receptor gene is associate with schizophrenia. Hum Mol Genet 6:577-582

11. Lesch KP, Bengel D, Heils A et al (1996) Association of anxiety-related traits with a polymorphism in the serotonin transporter gene regulatory region. Science 274:1527-1531

12. Lappalainen J, Dean M, Charbonneau L et al (1995) Mapping of serotonin 5HT1D, autoreceptor gene on chromosome 6 and direct analysis for sequence variants. Am J Med Genet 60:157-161

13. Hotamisligil GS, Breakefield XO (1991) Human monoamine oxidase A gene determines levels of enzyme activity. Am J Hum Genet 49:383-392
14. Ott J (1999) Analysis of human genetic linkage. Johns Hopkins University Press, Baltimore

15. Sham PC, Curtis D (1995) Monte Carlo tests for associations between disease and alleles at highly polymorphic loci. Ann Hum Genet 59:97-105

16. Maassen VanDenBrink A, Vergouwe MN, Ophoff RA et al (1998) 5-HT1B receptor polymorphism and clinical response to sumatriptan. Headache 38:288-291

17. Maassen VanDenBrink A, Vergouwe MN, Ophoff RA et al (1998) Chromosomal localization of the 5HT1F receptor gene: no evidence for involvement in response to sumatriptan in migraine patients. Am J Med Genet 77:415-420

18. Ophoff RA, Van Den Maagdenberg A, Roon KI et al (2001) The impact of pharmacogenetics for migraine. Eur J Pharmacol 413:1-10

19. Iadecola C (1998) Neurogenic control of the cerebral circulation: is dopamine minding the store? Nature Neurosci 1:263-265

20. Basu S, Nagy JA, Pal S et al (2001) The neurotransmitter dopamine inhibits angiogenesis induced by vascular permeability factor/vascular endothelial growth factor. Nature Med 7:569-574 